\title{
CONDICIONAMIENTOS DE LA DINÁMICA AMBIENTAL EN LAS DECISIONES HUMANAS SOBRE ASENTAMIENTO Y CIRCULACIÓN A LO LARGO EL ESTRECHO DE MAGALLANES DURANTE EL HOLOCENO TARDÍO
}

\author{
M. CECILIA PALLO
}

\begin{abstract}
RESUMEN
El estrecho de Magallanes fue el espacio de conexión más importante entre las poblaciones prehistóricas asentadas en Patagonia continental, insular y las de los archipiélagos chilenos del extremo sur de Sudamérica. La dinámica implícita en su conformación y configuración como una vía marítima debe haber establecido distintos niveles de posibilidades en la circulación y asentamiento de las poblaciones prehistóricas. Aquí se plantea un acercamiento biogeográfico a las características hidrodinámicas, geomorfológicas, ecológicas y climáticas del estrecho de Magallanes. Los sistemas de información geográfica (SIG) se proponen como una metodología eficiente para evaluar los límites establecidos por el Estrecho sobre las decisiones humanas de circulación e instalación en el espacio durante el Holoceno Tardío.
\end{abstract}

PALABRAS CLAVE: estrecho de Magallanes, Holoceno Tardío, uso humano del espacio, dinámica ambiental, SIG.

\section{ENVIRONMENTAL DYNAMIC CONSTRAINTS IN THE DECISIONS OF HUMAN SETTLEMENT AND CIRCULATION ALONG THE MAGELLAN STRAIT DURING THE LATE HOLOCENE}

\section{ABSTRACT}

The Strait or Magellan was the most important area of connection between the prehistoric peoples settled in Patagonia continental, insular and southernmost Chilean islands of South America. The dynamics inherent in its shape and configuration as a waterway must have set different levels of possibilities in the movement and the settlement of the prehistoric peoples. A biogeographic approach to the hydrodynamic, geomorphologic, ecological and climatic characteristics of the Magellan Strait is offered here. The geographical information systems (GIS) analysis is proposed as an efficient methodology to assess the boundaries that the Strait sets on human decisions concerning installation and movement during the Late Holocene.

KEY WORDS: Magellan Strait, Late Holocene, human use of space, environmental dynamics, GIS. 


\section{INTRODUCCIÓN}

El estrecho de Magallanes es una importante vía marítima que conecta el océano Pacífico con el océano Atlántico entre Patagonia meridional continental, la isla de Tierra del Fuego y los archipiélagos al sur de Chile. Su formación implicó una nueva barrera biogeográfica que inició un proceso de evolución humana divergente entre las poblaciones de la isla y el continente (Borrero 1989-90), dejando en aislamiento potencial a las poblaciones marítimas (Borrero 2001a) que se establecieron en los archipiélagos chilenos hacia el Holoceno Medio y Tardío (e.g. Ortiz Troncoso 1975, 1979 y 1989, Legoupil 2000; Morello et al. 2004).

La particular fisonomía biogeográfica del Estrecho es producto de su origen glaciar, el accionar de los vientos del $\mathrm{O}$, la marcada influencia de glaciares y de corrientes oceánicas (Cerdas 1993 en Salinas et al. 2004) y de sus características ecológicas (Panella et al. 1991 y Lecaros et al. 1991 en Valdenegro y Silva 2003). Tales elementos debieron constituir un paisaje heterogéneo en cuanto a las posibilidades para la movilidad y el asentamiento humanos. En particular, nos interesa evaluar la existencia de barreras temporarias (sensu Veth 1993) vinculadas con zonas de uso estacional o marginal (sensu Borrero 2004) durante el Holoceno Tardío. Para ellos se realizó un análisis espacial con SIG en el que se cruzó la información ambiental (geomorfológica, ecológica, hidrodinámica y climática) con la evidencia arqueológica (e.g. Ortiz Troncoso 1975, 1979 y 1989 , Legoupil 2000; Morello et al. 2004) y etnográfica (Emperaire 1963; Martinic 1989) publicada para el área del Estrecho. Si bien los datos ambientales son actuales, ciertas propiedades que condicionan la fisionomía biogeográfica del Estrecho se han mantenido relativamente constantes en el lapso que nos interesa. Esto hace referencia al carácter cerrado del estrecho de Magallanes, la presencia de los westerlies en su posición actual después del ca. 8200 años AP (ver McCulloch y Morello 2009) y la topografía y batimetría producto de la erosión glaciar y los hundimientos tectónicos (Valdenegro y Silva 2003). De modo que la variabilidad actual del paisaje constituye un marco de referencia (sensu Binford 2001) para establecer diferencias ambientales generales y cualitativas con las cuales confrontar la evidencia arqueológica y la información etnográfica referidas a las poblaciones de cazadores marítimos que habitaron el estrecho de Magallanes.

\section{FORMACIÓN Y PALEOAMBIENTE DEL ESTRECHO DE MAGALLANES}

Los estudios paleoambientales sugieren que luego del último máximo glaciar (LGM - 28000 a 20000 años AP), un rápido mejoramiento climático culminó con la formación del estrecho de Magallanes (Clapperton 1992; McCulloch et al. 1997). La retirada de los glaciares de la región central del Estrecho comenzó antes del ca. 14320 años AP (McCulloch et al. 2005) y finalizó en algún momento antes del ca. 10315 años AP. Durante este lapso el mar estaba más bajo que actualmente (ver Rabassa et al. 2008; McCulloch y Morello 2009), por lo que entre las angosturas existió un puente de tierra intermitente que unía el continente y Tierra del Fuego cuando desaparecían los lagos proglaciares (Clapperton 1992; McCulloch et al. 2005; Rabassa et al. 2008). Estos momentos delinearon las últimas posibilidades de cruce a pie por cazadores terrestres hacia la isla (McCulloch et al. 2005; McCulloch y Morello 2009), probablemente vinculadas con la ocupación humana más temprana del alero Tres Arroyos 1 de ca. 10500 años AP (Massone 2004, Massone y Prieto 2004). No obstante, Borrero (2001a) no descarta la posibilidad que hacia el ca. 11000 años AP ya hubiera gente en el área, siguiendo la margen $\mathrm{E}$ del bosque de Nothofagus/estepa que migró hacia los Andes australes y la cordillera Darwin (ver McCulloch y Morello 2009).

Con el mejoramiento climático del Holoceno aumentó la humedad, producto de la vuelta a su posición actual de los westerlies después del ca. 8200 años AP (ver McCulloch y Morello 2009). Más altas precipitaciones se extendieron hacia el E del Estrecho junto con el bosque de Nothofagus después del 10.000 años AP (McCulloch y Davies 2001). El mar ascendió, antiguos lagos glaciares (Skyring, Otway) establecieron comunicación con el océano Pacífico (Solari 2007) y algunos espacios cordilleranos se volvieron más accesibles (McCulloch y Davies 2001). Dentro de este escenario, el Estrecho se constituyó definitivamente hacia el ca. 8000 años AP con la disolución final de los casquetes de hielo (McCulloch y Morello 2009). Posteriormente, 
se asentaron las primeras poblaciones marítimas en los archipiélagos chilenos (Ortiz-Troncoso 1979 y 1989, Legoupil 1988, 2000; Morello et al. 2004; San Román 2005), con temperatura y humedad mayores que las actuales (McCulloch y Davies 2001). Durante la transgresión marina, que comenzó entre ca. 8265 años AP y 7490 años AP (McCulloch et al. 2005), el agua superó entre 4 y $7 \mathrm{~m}$ los niveles del mar actual (Rabassa et al. 2008). La casi horizontalidad de la incursión marina demuestra que no hubo movimientos tectónicos diferenciales en la zona central del estrecho de Magallanes y bahía Inútil durante los períodos tardiglacial y Holoceno (McCulloch y Morello 2009). Sin embargo, la ausencia de costas elevadas al sur del paso del Hambre sugiere que unidades geológicas individuales pueden haberse hundido durante este tiempo (McCulloch y Morello 2009). La reducción de la franja costera durante el Holoceno Medio, implicó una restricción en la disponibilidad de espacios al momento en que llegaban las primeras poblaciones marítimas, por lo que tales cambios debieron formar parte de su período de exploración y colonización de los canales (Borrero 1994-95). Luego de la transgresión marina y a medida que el mar descendía, nuevos ambientes costeros y vías de paso comenzaron a estar disponibles. En definitiva, las variaciones ambientales que experimentó el Holoceno, incluyendo las oscilaciones entre períodos de clima frío y cálido de momentos tardíos (Mercer 1970; Stine 1994), debió conformar un paisaje heterogéneo en términos de las posibilidades de asentamiento y circulación para las poblaciones humanas del estrecho de Magallanes. Asimismo, circunstancias tales como aislamiento potencial en la zona de archipiélagos, o extinciones de poblaciones locales en el norte de Tierra del Fuego pudieron ser posibles (Borrero 2001a).

\section{METODOLOGÍA Y PRESENTACIÓN DE LA INFORMACIÓN}

En un área ecológicamente heterogénea como es el estrecho de Magallanes, podemos esperar la existencia de una jerarquización en el uso humano del espacio vinculado, entre otras cosas, con la presencia de barreras biogeográficas (Borrero 2001b). Para evaluar esto se desarrolla un análisis de los datos ambientales junto con información sobre los sistemas de asentamiento y movilidad de las poblacio- nes marítimas durante el Holoceno Tardío. Distintas fuentes (información en formato SIG, publicaciones e imágenes satelitales) fueron consultadas para extraer datos sobre altura (SRTM-Shuttle Radar Topography Mission) $)^{1}$, pendiente y orientación del terreno, hidrografía (DIVA-GIS²), vegetación (DIVS-GIS, Luebert y P. Pliscoff 2009), clima (temperatura media anual y precipitación anual, WorldClim ${ }^{3}$ ) y características del estrecho de Magallanes en cuanto a su conformación, geomorfología costera, hidrodinámica y ecología. También se consideró la distribución de los cazadores marinos a partir de restos humanos con dietas marinas (Barberena 2002), registros etnohistóricos relevados por Martinic (1989) y sitios arqueológicos (e.g Ortiz Troncoso 1975; Morello et al. 2004), en particular aquellos que presentan artefactos manufacturados en obsidiana verde (ver Morello et al. 2004; Manzi 2004). La información relevada fue procesada en formato SIG a fin de poder evaluarla de manera conjunta.

\section{Área de estudio}

El estrecho de Magallanes (figura 1) es un canal interoceánico que se prolonga de $\mathrm{O}$ a $\mathrm{E}$ a través de $583 \mathrm{~km}$ de longitud y varía entre $3 \mathrm{~km}$ en la Primera Angostura a 35 o $40 \mathrm{~km}$ en el área de bahía Porvenir (Salinas et al. 2004). Su profundidad es mínima ( $28 \mathrm{~m}$ ) en las proximidades de la isla Magdalena y máxima $(1080 \mathrm{~m})$ en la zona de canales (Alveal et al. 1978). Esta constituido por flujos de agua que provienen de los océanos Pacífico, Atlántico y del Mar del Sur (Panella et al. 1991). Las aguas nunca se congelan y promedian entre $3^{\circ}$ a $11^{\circ} \mathrm{C}$ (Valdenegro y Silva 2003; Olave-Solar et al. 2008). Su circulación está fuertemente modulada por las corrientes de marea ${ }^{4}$, la geomorfología de la cuenca, particularmente por los estrechamientos en las angusturas, factores meteorológicos como los vientos del O (Salinas et al. 2004) y la batimetría (Valdenegro y Silva 2003). En su mayoría, las costas del archipiélago fueguino corresponden a líneas rocosas y acantiladas (Araya y Vergara 1982). Entre

1 SRTM (SHUTTLE RADAR TOPOGRAPHY MISSION): http://srtm.usgs.gov/

2 DIVA-GIS: http://www.diva-gis.org/

3 WORLDCLIM: http://biogeo.berkeley.edu/worldclim/ worldclim.htm

4 Movimientos horizontales o laterales del agua (R.L.D. 2008). 


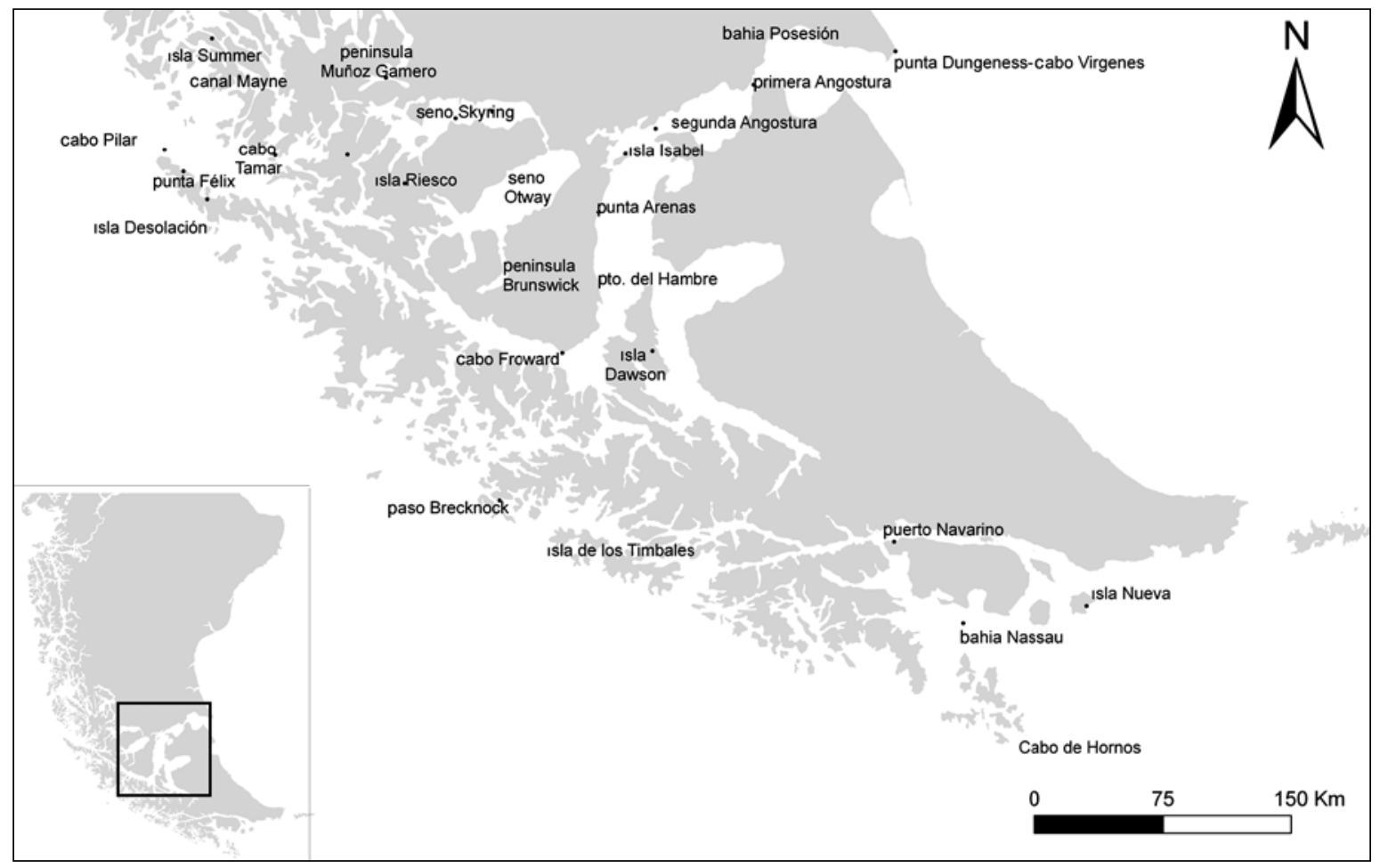

Fig. 1. Ubicación del estrecho de Magallanes y sectores de importancia mencionados en el texto.

la boca $\mathrm{O}$ hasta el Paso Ancho la profundidad (entre 1200 y los $600 \mathrm{~m}$ ) determina condiciones micromareales (mareas < a $2 \mathrm{~m}$ ) vinculadas con playas reducidas, de poca pendiente y baja energía (Prieto y Winslow 1992). En la Primera Angostura y punta Dúngeness imperan condiciones macromareales que permiten el desarrollo de extensas playas, con alta pendiente y moderada a alta energía (Prieto y Winslow 1992). Sectores de costas arenosos acompañados por acantilados se presentan en zonas de bahías lobulares al interior de los mares de Skyring y Otway y, en la costa de Tierra del Fuego (e.g bahía Inútil, Gente Grande, Felipe y Lomas, sensu Araya y Vergara 1982). En cabo Vírgenes y la bahía Posesión existen elevados acantilados activos de hasta $80 \mathrm{~m}$ de altura que dejan playas muy angostas y poco accesibles (Uribe y Zamora 1981). Finalmente, líneas litorales propias de fiordos se ubican en las costas que rodean a Puerto Natales, los senos Silva Palma y Wickham en la península Brunswick y la costa $S$ de Tierra del Fuego, frente a la isla Dawson (Araya y Vergara 1982).

Existen diversas unidades ambientales definidas para la región de Magallanes de acuerdo a sus valo- res medios de temperatura y precipitación mensual así como la distribución de los tipos de vegetación (ver la clasificación de tipos climáticos definidos por diversos autores según Köpper en CONAF 2009). La tendencia climática general es de tipo oceánico hacia la boca $\mathrm{O}$ y continental hacia la boca $\mathrm{E}$ del estrecho (di Casti y Hajek 1976; Santana et al. 2010). El clima de tundra isotérmica caracteriza las islas del S y $\mathrm{N}$ del estrecho de Magallanes (ver CONAF 2009), con promedios de $6^{\circ} \mathrm{C}$ de temperatura y precipitaciones entre ca. $4500 \mathrm{~mm}$ y ca. $1000 \mathrm{~mm}$ anuales, desciendo de $\mathrm{N}$ a SE. Estas islas son parte de la cordillera fragmentada por la acción permanente del hielo, con alturas inferiores a los 1000 msnm. La vegetación dominante es de tundra y bosque siempre verde (Luebert y P. Pliscoff 2009). El relieve no permite el desarrollo de grandes cuencas o sistemas hidrográficos; los más importantes se ubican en la isla Navarino y sus islas aledañas. Las nieves eternas aparecen por encima de los $700 \mathrm{msnm}$ sobre suelos desnudos, líquenes y musgos (Luebert y P. Pliscoff 2009) del archipiélago chileno y la cordillera Darwin (Tierra del Fuego). Corresponden al clima de hielo por efecto de altura con temperaturas que 
promedian los $-12^{\circ} \mathrm{C}$ (ver CONAF 2009). También algunos cerros elevados de las isla Santa Inés, Riesco y península Muñoz Gamero corresponden a este tipo climático (CONAF 2009).

En general, hacia los canales interiores el clima es templado y frío, aunque con variaciones zonales. La distribución de la temperatura está determinada, principalmente, por factores locales como la cobertura, la altitud y la topografía del terreno (Olave-Solari et al. 2008). Las zonas costeras con bosques mixtos de Nothofagus y las serranías (hasta $500 \mathrm{msnm}$ ) con bosque siempre verde y turberas (Luebert y P. Pliscoff 2009), mantienen características oceánicas y húmedas propias de la costa occidental del Estrecho (CONAF 2009). A las planicies intermedias de los mares interiores (entre 150 y 300 msnm) corresponde un clima transicional hacia la estepa, con presencia de matorral arborescente (Luebert y P. Pliscoff 2009), menores precipitaciones (promedios de ca. $600 \mathrm{~mm}$ anuales) y mayor amplitud térmica a medida que aumenta la distancia al mar (Figura 2). Los cuerpos de agua en este sector son los más abundantes (e.g. lago Riesco y los ríos de carácter permanentes como Prat, Boer y Grande en la península Riesco y, el lago Caballero y los ríos La Caleta y San Juan para la península Brunswick). Hacia el sector de puerto Natales se destacan también los lagos Balmaceda y Aníbal Pinto. Desde Punta Arenas a la boca oriental del estrecho, el clima es de estepa frío (Pisano 1977), con baja pluviometría (ca. 200 a $300 \mathrm{~mm}$ anuales) y temperaturas promedio más altas que el sector $\mathrm{O}\left(\right.$ e.g. $8^{\circ} \mathrm{C}$ en bahía Posesión, sensu Santana et al. 2010). También, existe un conjunto de cuerpos lagunares hacia el interior continental (e.g. Cabeza del Mar, del Toro y Los Patos) y en la isla Tierra del Fuego (e.g. Serrano y Los Cisnes). Para la boca oriental del estrecho se destacan ríos como Serrano y Oscar para Tierra del Fuego y, Susana y Kimiri Aike en la bahía Gregorio. Cabe señalar que la duración anual de los vientos del $\mathrm{O}$ y su intensidad anual (ca. $17 \mathrm{~km} / \mathrm{h}$ ) agravan tanto el efecto del frío como de la aridez en los distintos ambientes mencionados (di Casti y Hajek 1976).

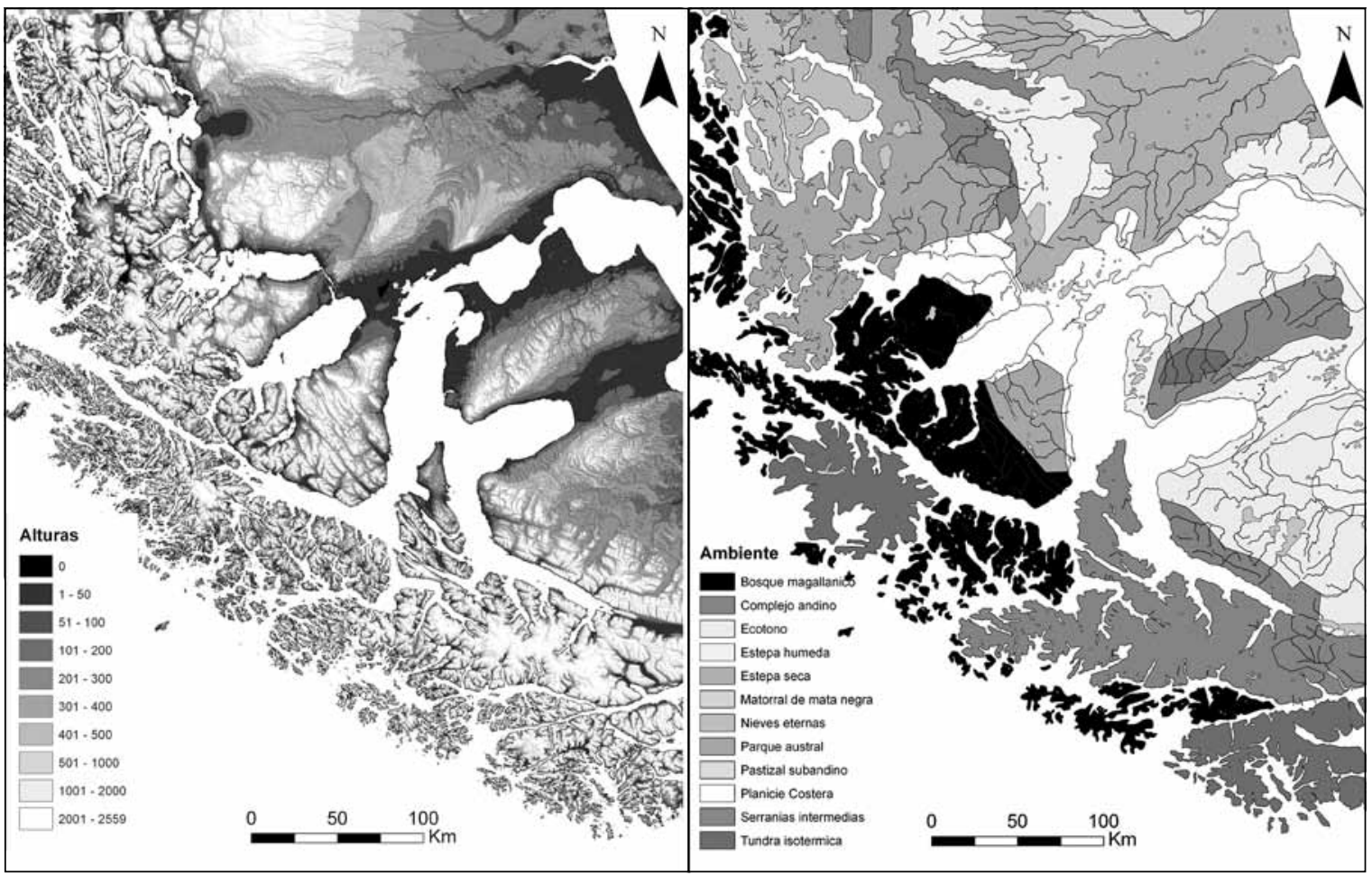

Fig. 2. Elevación del terreno y ambientes en el estrecho de Magallanes. 
Condiciones para la navegación canoera

Los relatos históricos mencionan que las canoas entre los grupos de los archipiélagos han sido de dos clases: desde el golfo de Penas hasta el Estrecho, la canoa de planchas cosidas y, a partir del Estrecho, la canoa de cortezas (ver Emperaire 1963). La primera era una adquisición técnica obtenida de los indígenas de Chiloé, se manejaba con remos y corresponde al área de extensión de las coníferas, alerces y cipreses con los que era construida. La segunda era la más característica del sector del Estrecho y correspondía al área de extensión del Nothofagus betuloides (coihue). Esta última, medía ca. $8 \mathrm{~m}$ de largo, $1 \mathrm{~m}$ de ancho y 1 $\mathrm{m}$ de profundidad y podía contener entre 9 y 10 personas. Estaba compuesta por tres partes que se mantenían unidas por varillas y costuras hechas con lianas, su forma era de media luna y se maniobraba con pagay. Los trozos de corteza formaban el piso junto con arena, piedras y conchas sobre las que se mantenía un fuego constante. Asimismo una piel de foca les servía a veces de vela, si el viento era favorable. Debido a que estas embarcaciones eran frágiles y vulnerables a las diferencias en la intensidad y rumbo del viento y el mar de fondo al interior del Estrecho, tales factores debieron generar condiciones selectivas sobre las áreas de navegación. Los datos aportados por el Servicio de Hidrografía Naval de la Armada Chilena ${ }^{5}$ nos permiten hacer un análisis comparativo de tales factores hidrodinámicos entre las distintas zonas del estrecho de Magallanes.

Como se mencionó anteriormente, los vientos predominantes son del cuadrante $\mathrm{O}$ (Asenjo Riquelme 2009). Estos vientos configuran un clima húmedo con cielos cerrados y tempestuosos todo el año, y complican la navegación costera, aumentando la corriente y arrastrando la lluvia. En la boca occidental las ráfagas de viento del $\mathrm{O}$ y $\mathrm{NO}$, conocidas como williwaws o chubascos, son particularmente intensas en invierno, pudiendo alcanzar hasta 120 nudos aunque en cortos lapsos (SHOA 2009). Suelen ser acompañadas por caída de lluvia o granizo que produce cerrazones y levantan olas de hasta $8 \mathrm{~m}$ de alto. En primavera y verano, son más frecuentes los vientos del S (Santana et al. 2010) y mayores

5 http://meteoarmada.directemar.cl/site/pronosticos/pronostico_canales_australes.html. las horas de luz diurna (ca. 20hs actualmente), pero pueden presentarse temporales del $\mathrm{SO}$, como el viento local panteonero, con dirección O-NO y que puede alcanzar hasta $120 \mathrm{~km} / \mathrm{h}$ (Asenjo Riquelme 2009). Al accionar del viento se suman la permanente mar de leva ${ }^{6}$ las nevadas invernales que complican la navegación sobre el sector $\mathrm{O}$ del Estrecho. En invierno, se intensifican el frío y la caída de nieve, mientras que la luz diurna es mucho menor (ca. 6 hs). La primavera es la época de deshielo, y cuando mayor cantidad de témpanos se observa en el mar, en particular en el borde SO y S del Estrecho, donde los mantos de hielo que caen al mar, o bien se retraen, echando agua a los canales por pequeñas cataratas que refuerzan el efecto de los vientos encajonados. Lugares como el paso fiordo Parry-Lapataia o Yendegaia, sobre el arco de islas al S del Estrecho, debieron estar disponibles sólo temporalmente de acuerdo con los avances y retrocesos de los glaciares. Hacia el interior, como en los mares de Skyring y Otway, las aguas son más tranquilas (Panella et al. 1991) aunque pueden hallarse témpanos flotantes (e.g. en los canales Sarmiento y Gajardo).

Para un mismo día y horario de la primavera se obtuvieron valores hidrodinámicos del Estrecho durante el día y la tarde/noche (Tabla 1). Durante el día, los vientos predominantes son del cuadrante S, propios de la época de verano (Santana et al. 2010), y la intensidad del viento es relativamente pareja, aunque se observan menores velocidades hacia los canales interiores. Las estaciones expuestas al mar abierto (canal Brecknock y estrecho Nelson) y del sur fueguino (puerto Navarino, bahía Nassau y cabo de Hornos) presentan intensidades de viento mayores. Los registros no manifiestan grandes diferencias de intensidad entre el día y la noche pero sí en la

6 El fenómeno conocido como "Mar de Leva", consiste en el aumento anormal de la altura del oleaje, aumento que es ocasionado por el efecto de fricción entre la superficie del mar y el viento, el cual es intensificado con el paso de sistemas atmosféricos de mal tiempo (bajas presiones) que empujan las aguas oceánicas hacia la costa causando oleaje fuerte. El tamaño de las olas formadas depende de la velocidad y el tiempo que persista la misma velocidad de viento. La incidencia de los efectos de este fenómeno sobre cualquier tipo de embarcación son mucho mas fuertes en las áreas costeras ya que la altura de la ola aumenta en la medida que encuentre cambios en el nivel de la línea de costa. También se causan daños en la costa, provocando inundaciones en sectores aledaños a las playas y originando además diferentes grados de erosión. 
dirección del viento, rotando desde el S hacia el O. El tamaño de las olas también aumenta hacia las estaciones con conexión al mar abierto (estrecho Nelson, canal Brecknock, punta Dungeness y cabo de Hornos), disminuyendo hacia el interior del estrecho y los senos internos. Las diferencias de mar de fondo se mantienen relativamente estables para el registro de tarde /noche, aunque aumentan levemente los valores generales. Asimismo, hemos podido comparar los registros meteorológicos de la tabla 1 con otros en los que domina el viento $O$. Con vientos del cuadrante $\mathrm{O}$, los valores generales de velocidad de viento y en particular, el tamaño de olas aumentan. Esto es más notorio para las estaciones más externas, aunque las diferencias relativas entre estaciones se mantienen. De modo que los valores presentados en la tabla 1 son representativos a nivel cualitativo de los distintos sectores del estrecho pero están disminuidos con respecto a los valores más frecuentes, con vientos del O. Por ejemplo, con vientos del O, Punta Arenas y el cabo de Hornos registra valores de vientos similares, del cuadrante O/SO con velocidad entre 20 y 25 para el primero y, 25 y 30 nudos para el segundo. Sin embargo, en Punta Arenas la mar es rizada mientras que en el cabo de Hornos las olas tienen tamaños entre 2 y 3 mts.

\section{Condiciones ecológicas del} estrecho de Magallanes

Los estudios etnográficos han demostrado que existe una correlación negativa entre la importancia de los recursos marinos para la subsistencia y el tamaño de los rangos de acción o territorios (e.g. Binford 2001; Kelly 1995). La variabilidad actual de la biomasa animal a lo largo del estrecho de Magallanes (Magazzú et al. 1996; Pizarro Solari 2004; Sielfeld et al.1978; Venegas y Sielfeld 1979) puede ser útil para generar modelos explicativos sobre las estrategias de movilidad y subsistencia que las poblaciones humanas desarrollaron en una escala amplia (Binford 2001).

En el estrecho de Magallanes existen alrededor de 34 especies de aves marinas, dos especies de lobos marinos (Sielfeld et al.1978) y 21 especies de cetáceos (Gibbons et al. 2000). Los principales apostaderos de lobos marinos y sitios de nidificación de aves marinas están localizados en el litoral oceánico (figura 3). Mientras el lobo fino austral ubica sus colonias casi exclusivamente en estas zonas, el lobo común dispone de similar cantidad de apostaderos en canales y senos interiores y, en el litoral exterior (Venegas y Sielfeld 1979). Sin embargo, para ambas especies las loberías con las mayores densidades se sitúan en las costas exteriores, en

Tabla 1. Se presentan los datos sobre las condiciones del viento (intensidad y rumbo) y el tamaño de las olas (mar de fondo) en el estrecho de Magallanes. Los mismos corresponden a un mismo día de la época de primavera durante el año 2011 , siendo los dos 2 pronósticos diarios (diurno y vespertino) que ofrecen cada una de las estaciones meteorológicas.

\begin{tabular}{|c|c|c|c|c|c|c|}
\hline \multirow{2}{*}{$\begin{array}{c}\text { EPOCA DE PRIMAVERA } \\
\text { 21-09-2011 } \\
\text { Estacion meteorológica }\end{array}$} & \multicolumn{3}{|c|}{ DIA } & \multicolumn{3}{|c|}{ TARDE/NOCHE } \\
\hline & $\begin{array}{l}\text { Intensidad } \\
\text { del viento }\end{array}$ & Rumbo & Mar de fondo & $\begin{array}{l}\text { Intensidad } \\
\text { del viento }\end{array}$ & Rumbo & Mar de fondo \\
\hline ESTRECHO NELSON & 10/15 NDS & SE & $2.0 / 1.01010$ & 5/15 NDS & S/SE & 1.0/2.0 MTS. \\
\hline PUERTO NATALES & 5/10 NDS & $\mathrm{NE}$ & MAR LLANA & 2/12 NDS & $\mathrm{N} / \mathrm{NE}$ & MAR LLANA \\
\hline TASO TAMAR & 10/15 NDS & SE & $1.0 / 2.0$ & 6/16 NDS & S/SE & 1.5/2.0 MTS. \\
\hline FELIX/FROOARD & 5/10 NDS & $\mathrm{S} / \mathrm{SO}$ & $0.2 / 0.5$ & 2/12 NDS & $\mathrm{SO} / \mathrm{S}$ & 0.5/1.0 MTS. \\
\hline FROWARD/PTA.DELGA & 5/10 NDS & NO & AR LLANA & 5/15 NDS & $\mathrm{O} / \mathrm{SO}$ & 0.5/1.0 MTS. \\
\hline PUNTA ARENAS & 5/10 NDS & $\mathrm{O} / \mathrm{NO}$ & MAR LLANA & 5/15 NDS & $\mathrm{O} /$ & MAR LLANA \\
\hline PTA.DELGADA/DUI & $5 / 1$ & & & DS & & \\
\hline CANAL BRECKN & $10 / 15$ NDS & $\mathrm{S} / \mathrm{SO}$ & MTS. & 6/16 NDS & $\mathrm{O} / \mathrm{NO}$ & MTS. \\
\hline TIMBALES/PTO. NAVARINO & $5 / 10$ & $\mathrm{SO}$ & $0.2 / 0.5 \mathrm{MTS}$. & 6/16 NDS & $\mathrm{O} / \mathrm{NO}$ & 0.5/1.0 MTS. \\
\hline PTO NAVARINO/I. NUEVA & $20 / 15$ NDS & $\mathrm{SO}$ & 0.5/1.0 MTS. & 14/20 NDS & $\mathrm{O} / \mathrm{SO}$ & 0.5/1.5 MTS. \\
\hline PTO. WILLIAMS & 10/5 NDS & $\mathrm{SO}$ & MAR LLANA & 6/16 NDS & $\mathrm{O} / \mathrm{NO}$ & MAR RIZADA \\
\hline B. NASSAU/C. HORNOS & $20 / 25$ NDS & SW/W & 1.5/2.0 MTS & $15 / 25$ NDS & $\mathrm{O} / \mathrm{SO}$ & 0.5/1.5 MTS. \\
\hline CABO DE HORNOS & 15/20 NDS & SW/W & 3.0/2.0 MTS. & $20 / 30$ & $\mathrm{O} / \mathrm{SO}$ & 2.0/3.0 MTS. \\
\hline
\end{tabular}




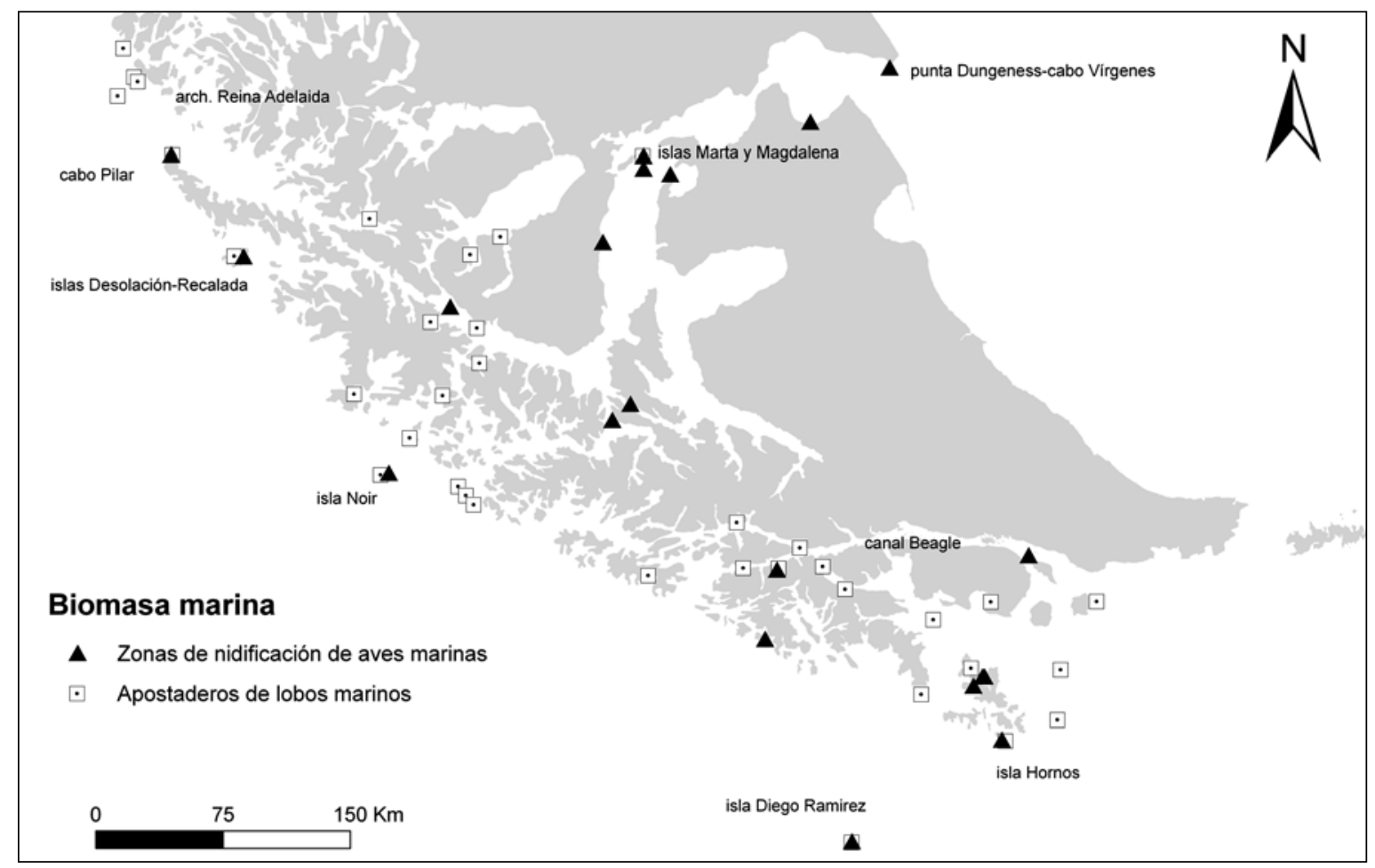

Fig. 3. Distribución de biomasa marina en el estrecho de Magallanes. En el mapa se muestran los principales apostaderos de lobos marinos y sitios de nidificación de aves marinas, en particular los pingüinos.

particular en el archipiélago Reina Adelaida, el sector isla Desolación-isla Recalada y las áreas cercanas al canal Beagle (Sielfeld et al.1978; Pizarro Solari 2004). En algunos casos, los lugares de nidificación de las aves marinas, coinciden con los apostaderos de lobos marinos actuales (e.g cabo Pilar, isla Marta, isla Hornos). Esto se debe a que algunas especies, como los pingüinos, nidifican exclusivamente en las costas exteriores del estrecho (Venegas y Sielfeld 1979). Los principales centros reproductivos de pingüinos y de otras aves marinas son las islas Noir, Magdalena y Diego Ramírez (Pizarro Solari 2004). En particular, mamíferos menores (e.g Caperea marginata, Delphinidae y Phocoenidae) y cetáceos emplean el estrecho de Magallanes como ruta migratoria y son mayores hacia la boca oriental del estrecho y el Atlántico austral. Los mayores avistajes de cetáceos se registraron entre cabo Froward y Segunda Angostura, mientras que hacia la boca atlántica la alta presencia de avistajes se sumó al gran número de varamientos de cetáceos (Gibbons et al. 2000). Desde la boca O del Estrecho al cabo Froward y en los mares interiores (Skyring, Otway y
Almirantazgo) los cetáceos avistados fueron mucho menores (Gibbons et al. 2000).

Mientras los principales apostaderos de lobos marinos se registran en las islas externas, las aves marinas y los cetáceos se distribuyen de manera más amplia, en particular hacia el interior y la boca oriental del estrecho. Por ejemplo, existe una colonia de pingüinos en punta Dungeness-cabo Vírgenes, más allá del límite E de las colonias de lobos marinos en la isla Marta. No obstante, cabe señalar que el estudio de los depósitos de huesos asociados al área de nidificación de pingüinos señala que tienen un origen reciente, posiblemente vinculado con el s. XX (Cruz et al. 2010). Al igual que este sector, otras áreas de nidificación pudieron no estar disponibles en el pasado o variar su localización. La información biogeográfica actual resulta orientativa principalmente sobre las preferencias de hábitat entre aves y mamíferos marinos, las cuales debieron ser factores relativamente constantes en el tiempo. En relación con esto, algunos motivos que explicarían el atractivo del litoral exterior de Magallanes para distintas especies marinas estarían vinculados con 
la selección de costas acantiladas y rocosas (Pizarro Solari 2004) o con la presencia de moluscos y algas propias de estas zonas expuestas a las rompientes y que no se hallan en el interior del estrecho (Venegas y Silelfeld 1979). Por su parte, la existencia de playas someras y de baja pendiente que actúan como trampas de cetáceos explicaría el mayor número de varamientos registrado en las bahías Lomas, Posesión y Dungeness (Gibbons et al. 2000).

Distribución de los cazadores marítimos: sitios arqueológicos y documentos históricos

Existen distintos ítems diagnósticos que pueden entenderse como una expresión de los rangos de acción de las poblaciones canoeras y por lo tanto, permiten evaluar zonas de distribución y concentración poblacional (figura 4). Los marcadores que empleamos refieren a sitios arqueológicos con artefactos manufacturados en obsidiana verde, los cuales constituyen un bien característico de los grupos canoeros (Morello et al. 2004), restos humanos con valores de isótopos estables correspondientes a dietas marinas (ver Barberena 2002, 2008) e información etnohistórica sobre el avistaje de grupos canoeros entre los s. XIX y XX (Martinic 1989). Cabe señalar que nuestras observaciones son relativas debido a que posiblemente el registro arqueológico refleja las zonas más estudiadas por los arqueólogos mientas que los registros históricos corresponde al momento de contacto con la población blanca, implicando nuevas formas circulación y de uso del espacio para las poblaciones del archipiélago.

Las mayores concentraciones de sitios con artefactos manufacturados en obsidiana verde en los mares de Syring y Otway señalan el sector de aguas interiores como el de más alta redundancia ocupacional (e.g. Legoupil 2000; Morello et al. 2000, 2004; Ortiz Troncoso 1973, 1975; San Román et al. 2009). El mar de Skyring también cuenta con datos sobre restos humanos asociados con dietas marinas (Ea. Lola y Ponsonby), aunque

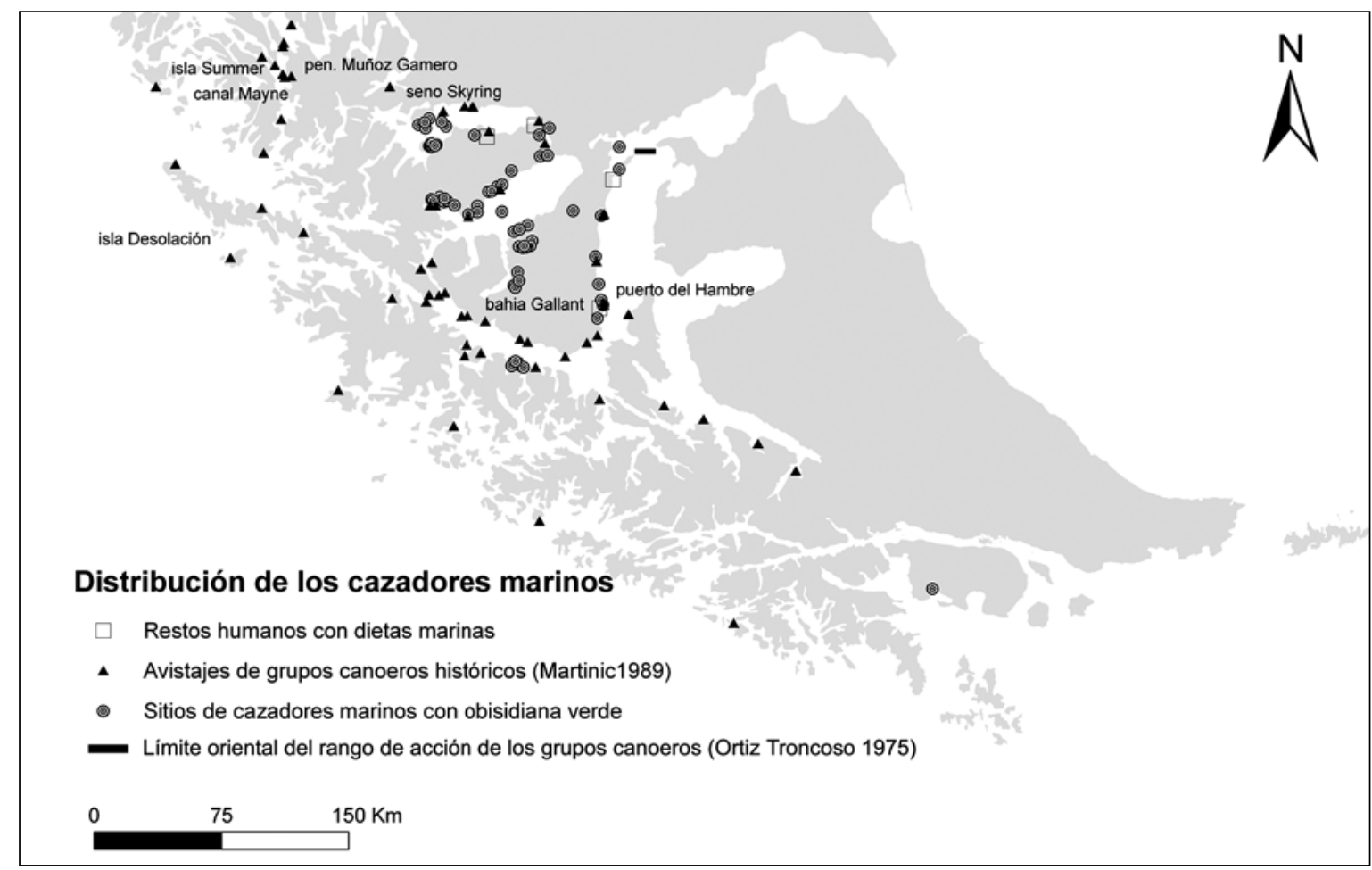

Fig. 4. Mapa con distintos marcadores diagnósticos que nos permiten estimar la expresión de los rangos de acción de las poblaciones canoeras: sitios pertenecientes a cazadores marítimos con presencia de artefactos manufacturados en obsidiana verde, restos humanos con valores de isótopos estables correspondientes a dietas marinas y lugares en que fueron avistados grupos canoeros entre los s.XIX y XX. 
no está clara su cronología (ver Barberena 2002). Los registro etnohistóricos también señalan mayores concentraciones hacia los mares interiores, aunque muestran una distribución más amplia hacia otras áreas del Estrecho. En los relatos del s. XX las principales concentraciones permanentes de población marítima (ver Martinic 1989) hacen referencia al área NO de la península Muñoz Gamero vinculada con puerto Bueno, el sector de canales MayneGray y el puerto Ramírez y, los alrededores de la isla Summer. También, toma notoriedad el área O del seno Skyring y las vías que lo comunican con la península Muñoz Gamero.

Sobre el estrecho propiamente dicho se destacan por un lado, las áreas entre bahía ForntescueGallant y puerto del Hambre y por el otro, la bahía Desolación y sus alrededores (sobre el arco de archipiélagos al S del Estrecho), todas estas mencionadas especialmente en relatos del s. XIX (Martinic 1989). El sector de bahía Forntescue-Gallant y puerto del Hambre también presenta sitios arqueológicos tanto con artefactos manufacturados en obsidiana verde como con restos humanos vinculados a dietas marítimas (Punta Santa Ana y Bahía Laredo). Las amplias evidencias arqueológica e histórica para este sector también permiten asociarlos con zonas de uso frecuente. En los sectores de islas externas del Estrecho, si bien la evidencia arqueológica es escasa (e.g. ver Ocampo y Rivas 2000; Morello et al. 2004), los relatos históricos recogidos por Martinic (1989) permiten ampliar el panorama hacia las bahías y caletas sobre la costa $\mathrm{S}$ del estrecho de Magallanes. Estos sectores debieron ser de paraje frecuente a juzgar por la presencia de campamentos y toldos. Por su parte, a excepción del sector de bahía Desolación, es notorio que las costas externas del archipiélago S, sobre el Pacífico Sur, sólo cuentan con registros de presencia indígena y canoas, sin indicios de campamentos estables.

\section{DISCUSIÓN}

\section{El estrecho de Magallanes como una barrera biogeográfica}

Existen diversas barreras biogeográficas que pueden constituir límites permanentes o temporarios a la expansión humana. El clima y la geografía que caracterizan a Patagonia Meridional no sugieren la existencia de barreras estables (Borrero y Carballo Marina 1998; aunque ver Borrero 1999 para la transición Pleistoceno-Holoceno). De modo que, la distinción entre barreras temporarias (Veth 1993) vinculadas a espacios de uso marginal y las áreas comprendidas dentro de los rangos de acción de una población humana, puede ser de gran utilidad para comprender la señal arqueológica en el estrecho de Magallanes.

Para evitar los vaivenes de la corriente, la navegación canoera debió implicar viajes cercanos a la costa (Legoupil 2000). Bajo condiciones similares, la dirección del viento, la geomorfología costera y la amplitud de marea debieron acentuar o disminuir las diferencias entre los distintos sectores. Las condiciones menos favorables para la navegación canoera debieron vincularse con las costas externas del archipiélago fueguino, puesto que las líneas rocosas y acantiladas (Araya y Vergara 1982) ofrecen menos resistencia a la energía del oleaje mientras que el viento del $\mathrm{O}$ genera olas de mayor tamaño. A diferencia de ello, las costas interiores del archipiélago hasta el Paso Ancho, si bien presentan costas reducidas (Araya y Vergara 1982), sus condiciones micromareales determinan playas de poca pendiente y baja energía (Prieto y Winslow 1992), que mejoran las condiciones de navegabilidad. El aislamiento y las geoformas cerradas (e.g. las bahías en los mares de Skyring y Otway) e intrincadas (e.g. los fiordos en las costas de Puerto Natales) cercanas al continente generan las mejores condiciones para la estabilidad hidrodinámica. Por su parte, el seno Almirantazgo y los sectores próximos presentan alto dinamismo por el estrés del viento incluyendo la presencia de glaciares (Araya y Vergara 1982). Las condiciones menos óptimas de navegabilidad debieron acentuarse desde la Primera Angostura y a medida que se alcanzaba la boca oriental del estrecho, siendo que su hidrodinámica esta fuertemente modulada por su cercanía al mar abierto, la mayor amplitud de marea y, las costas de alta energía (Prieto y Winslow 1992; Uribe y Zamora 1981) con mayor exposición a los vientos y el oleaje. Sugerimos entonces que las condiciones hidrodinámicas más propicias para la navegabilidad canoera se vinculan con los senos interiores y el canal del estrecho llegando hasta el paso Ancho. En particular este último, pudo conformar una ruta más segura hacia la isla de Tierra 
del Fuego antes que un cruce por las angosturas. Las huellas de campamentos alacalufes en las costas de la isla Dawson, del golfo de Almirantazgo y del canal Gabriel (Emperaire 1963) así como la existencia de contactos entre grupos Alacalufes y Onas en las cercanías de la bahía Inútil (Emperaire 1963), apuntan a que los contactos deben haberse establecido más regularmente a partir del Paso Ancho antes que desde áreas más al oriente. En este sentido, la propuesta de la isla Isabel como el límite más oriental del rango de acción de los pueblos canoeros (Ortiz Troncoso 1975), podría vincularse con las mayores dificultades de navegabilidad hacia la boca oriental, al menos en ciertas épocas del año. Sumado a ello, la menor concentración general de biomasa marina desde las angosturas hacia la boca oriental debió ser otro factor para la marginalización de este sector dentro del rango de acción de las poblaciones marítimas. No obstante, existen evidencias vinculada con ocupaciones estacionales para la mitad oriental del Estrecho (Ortiz Troncoso 1975). La mayor presencia de restos de cetáceos varados en las costas orientales (Gibbons et al. 2000) podría haber sido un motivo para visitar este sector.

Por el contario, las islas y archipiélagos externos si bien no ofrecen las condiciones más óptimas para una navegación en canoa, debieron motivar visitas vinculadas con fines específicos (Borrero 2001). En particular, nos referimos a la obtención de recursos, teniendo en cuenta que existe una alta concentración actual de loberías y zonas de nidificación de aves marinas (Sielfeld et al.1978; Pizarro Solari 2004) y que los golfos, canales y bahías abiertas al Pacífico, como los canales Cockburn y Magdalena, son importantes rutas de desplazamiento de lobos marinos (Venegas 2001). Los sitios próximos al Pacífico, en las bahías de las islas Desolación y Santa Inés, empleados como lugares de paso y de habitación temporal entre los alacalufes históricos (Emperaire 1963) pudieron vincularse con esta situación. Asimismo, si bien las costas que miran al Pacífico y al paso Drake son las que concentran la mayor biomasa marina, las márgenes sobre el Estrecho debieron ser más frecuentadas, debido a que eran las accesibles para navegar. El más alto número de avistajes de grupos históricos en estos espacios antes que en sectores de mar abierto (Martinic 1989) avalan esta idea.
En el corto plazo, el clima y la estación del año debieron ser factores influyentes en las decisiones sobre los sectores a navegar y la duración de los derroteros por el Estrecho. En el Holoceno Tardío el clima era ventoso y seco (Prieto 1999 en Morello et al. 1999), lo que debió afectar de manera especial las zonas con conexión directa al océano Pacífico y Atlántico, y las islas externas al S y E del estrecho. En otoño-invierno, la mayor presencia de nieve y mantos de hielo debió acentuar las diferencias de previsibilidad entre estos espacios y otros del estrecho, promoviendo el uso estacional de los primeros. La época de primaveraverano debió promover los derroteros más extensos y hacia zonas menos favorables debido a que, si bien los vientos del O se intensifican, la caída de nieve es mucho menor y las horas de luz diurna se prolongan (ver Endlicher y Santana 1988). A largo plazo, el influjo de los cambios en el nivel del mar durante del Holoceno (McCulloch y Davies 2001) debió promover una reestructuración del sistema de movilidad y asentamiento canoero. Los datos euso-isostáticos para la región (ver Legoupil 2003) manifiestan procesos de aparición de nuevos espacios luego de la transgresión marina. También los sitios más antiguos (e.g. Bahía Buena, Bahía Colorada, Englefield 1, Punta Santa Ana) se hallan sobre antiguos niveles de playa (Legoupil 1988; San Román et al. 2002), mientras que los núcleos recientes, suelen ubicarse en cotas que no superan los 2 m.s.n.m. actual (Legoupil y Fontugne 1997; San Román et al. 2002). Esta nueva configuración debió promover la exploración y ocupación de nuevos espacios (sensu Borrero 1994-95), incluyendo nuevas vías de comunicación, algunas de las cuales pudieron estar vinculadas con los pasos de indios documentados en tiempos históricos (Emperaire 1963; Emperaire y Laming 1961; Lagoupil 2000; Prieto et al. 2000).

\section{Ocupaciones humanas costeras: asentamientos permanentes y temporarios}

Stuart (1983) señaló que las condiciones climáticas y de mareas altamente variables en el Cabo de Hornos, explicarían la supuesta "falta de organización" (Stuart 1983: 24) en los movimientos y la subsistencia del grupo Yagán. La situación pudo ser diferente en el Estrecho, en particular en los canales interiores, los cuales debieron ofrecer una mayor estabilidad hidrodinámica debido a que forman cuencas semicerradas con escaso oleaje, playas 
estables, amplias y bien orientadas. Los registros históricos (Martinic 1989) y los sitios arqueológicos (e.g. ver Ortiz-Troncoso 1979 y 1989; Legoupil 2000; Morello et al. 2001, 2004; San Román et al. 2002) también señalan que la ocupación siempre estuvo ligada a una instalación sobre la playa y en costas reparadas de los vientos del O. El acceso a ambientes heterogéneos, fuentes de agua permanentes y la presencia de puertos naturales hicieron de estos espacios las zonas más óptimas para una ocupación prolongada.

El alto grado de especialización en el aprovechamiento de mamíferos marinos, tanto para momentos tempranos como tardíos (Legoupil y Fontugne 1997; San Román 2010, 2011) debió favorecer el asentamiento estacional sobre litoral pacífico donde se concentra la más alta productividad marina del Estrecho (Sielfeld et al.1978; Pizarro Solari 2004; Gibbons et al. 2000). Las visitas de estos espacios debió ocurrir durante la época de primavera-verano, vinculada a la explotación de colonias de reproducción (San Román 2010) y mejores condiciones climáticas. No obstante, algunos apostaderos al interior de los senos y en sectores próximos (e.g. mar de Otway, mar de Skyring e isla Carlos III) junto con otros recursos de las bahías (peces, aves, ballenas y mariscos) y las pampas interiores (guanacos) debieron favorecer instalaciones más duraderas, implicando rangos de acción más pequeños a causa de los menores costos de búsqueda de recursos, en particular durante momentos de mayor rigurosidad climática. Sumado a ello, el intercambio entre Alacalufes y Tehuelches en momentos históricos (Fitz Roy en Emperaire 1963) y las distribuciones de artefactos manufacturados en obsidiana verde (ver Morello et al. 2004) señalan los senos interiores como un área crítica en la circulación e interacción entre poblaciones marítimas y terrestres, durante buena parte del Holoceno. Por su parte, la costa norte del Estrecho desde punta Santa Ana hasta Punta Arenas también ha sido una de las más frecuentadas en tiempos históricos y previos (Emperaire 1963; Martinic 1989; Morello et al. 2001; 2004; Ortiz Troncoso 1975; Stern y Prieto 1991), posiblemente vinculada con buenas condiciones hidrodinámicas, disponibilidad de recursos marinos como cetáceos y altas posibilidades para el establecimiento contactos con otros grupos.

\section{CONCLUSIONES}

Las diferencias zonales a lo largo del Estrecho permiten sugerir que las entradas del Pacífico y el Atlántico así como las islas y archipiélagos exteriores debieron ser desfavorables para la navegación canoera. En particular las márgenes exteriores del arco de islas fueguinas debieron tener un uso marginal, vinculado a la obtención de recursos marinos. Las costas interiores sobre el Estrecho debieron estar integradas de manera más frecuente a los rangos de acción de los grupos canoeros, al igual que los sectores de senos interiores y la costa $\mathrm{N}$ del Estrecho hasta el Paso Ancho. Estos últimos debieron sostener las condiciones más óptimas para la navegación canoera y el asentamiento humano a largo plazo. Asimismo, ofrecían buenas posibilidades para la obtención de recursos marinos y terrestres y el establecimiento de comunicaciones con otros grupos, continentales y de la isla de Tierra del Fuego. Hacia el E del paso Ancho y la isla Isabel la dinámica marina se vuelve mucho más compleja mientras que la disponibilidad de fauna marina disminuye notablemente. Creemos que la propuesta de Ortiz Troncoso (1975) sobre el límite E del rango de acción de las poblaciones marítimas podría vincularse con la dinámica ambiental propia del sector entre las angosturas y el Atlántico, la cual determina que sea un área marginal con respecto a los sectores occidentales.

\section{AGRADECIMIENTOS}

Gracias a Luis Borrero por sugerir ideas para este trabajo. Agradezco a él y a Lorena L'Heureux por su lectura crítica y comentarios sobre una versión previa. También, las sugerencias aportadas por los evaluadores fueron de gran ayuda para mejorar este trabajo. Lo aquí vertido es de mi exclusiva responsabilidad.

\section{BIBLIOGRAFÍA}

ALVEAL, K., H. ROMO y J. VALENZUELA 1973. Consideraciones ecológicas de las regiones de Valparaíso y de Magallanes. Revista de Biología Marina, 15(1):1-29.

ASENJO RIQUELME, C. 2009. Navegación y operación en aguas Antárticas. Tesis de Licenciatura, Facultad de Ciencias de la Ingeniería, Universidad de Chile, MS, Valdivia. 
ARAYA VERGARA, J.F 1982. Análisis de la localización de los procesos y formas predominantes de la línea litoral de Chile: Observación preliminar. Informaciones Geografías de Chile, 29: 35-55.

BAILEY, G. y I. DAVIDSON 1983. Site Exploitation Territories and Topography: Two Case Studies from Palaeolithic Spain. Journal of Archaeological Science, 10 (2):87-115.

BARBERENA, R. 2002. Los límites del mar. Isótopos estables en Patagonia meridional. Sociedad Argentina de Antropología, Buenos Aires.

BINFORD, L. 2001. Constructing Frames of Reference. An Analytical Method for Archaeological Theory Building Using Ethnographic and Environmental Data Sets. University of California Press, California.

BORRERO, L.A. 1989-90. Evolución cultural divergente en la Patagonia Austral. Anales del Instituto de la Patagonia, Serie Cs. Sociales, 19:133-140.

1994-1995 Arqueología de la Patagonia. Palimpsesto, 4: 9-69.

1999. Human Dispersal and climatic conditions during Late Pleistocene times in Fuego-Patagonia. Quaternary International, 53-54: 93-99.

2001a. El poblamiento de la Patagonia. Toldo, milodones y volcanes. Emecé Editores. Buenos Aires. 2001b. Cambios, continuidades, discontinuidades: discusiones sobre arqueología de Fuego-Patagonia. En: Historia Prehispánica Argentina. Berberián E. y A. Nielsen (eds.). Brujas. Tomo II: 815-838, Córdoba. 2004. The Archaeozoology of Andean 'Dead Ends' in Patagonia: Living near the Continental Ice Cap. En: Colonisation, Migration and Marginal Areas. A Zooarchaeological approach. M. S. Mondini; A. S. Muñoz y S. Wickler (eds.), Oxbow Books, pp. 55-61, Oakville. 2007. Proyecto PICT 02046: Visitas, intercambio y la zona vacía. Informe ANCyT, MS, Buenos Aires.

BORRERO, L.A. y F. CARBALLO MARINA 1998. Proyecto Magallania: La cuenca superior del río Santa Cruz. En: Arqueología de la Patagonia Meridional. Proyecto Magallania. L. A. Borrero (ed), Ediciones Búsqueda de Ayllu, pp. 11-27, Concepción del Uruguay.

BORRERO, L. A., F. MARTIN y R. BARBERENA Visits, "Fuegians," and Information Networks. En: The rol of information in hunter-gatherer band level societies. W. Lovis, R. Whallon, R. Hitchcock (eds.), Cotsen Institute of Archaeology Press, UCLA, pp. 249-296, Los Angeles.

CASAMIQUELA, R. M. 1973. Alacalufes, canoeros occidentales y pueblos marginales o metamórficos. Nota Crítica, Relaciones, Sociedad Argentina de Antropología 7: 125-143.
CLAPPERTON, C.M. 1992. La última glaciación y deglaciación en el estrecho de Magallanes: implicaciones para el poblamiento de Tierra del Fuego. Anales del Instituto de la Patagonia, Serie Ciencias Humanas, 21:113-128.

CONAF 2009. Plan de desarrollo local. Área de desarrollo preferencial: Seno Obstrucción-Villa Renoval (20092011). Disponible en Internet: h ttp://www.docstoc.com.

DI CASTRI, F. y E. HAJEK 1976. Bioclimatología de Chile. Dirección de Investigación, Vicerrectoría académica, Pontificia Universidad Católica de Chile, 128 pp, Santiago.

EMPERAIRE, J.1963. Los nómades del mar. Ediciones de la Universidad de Chile, Santiago de Chile.

1988. Paisajes y hombres prehistóricos de la Patagonia. Anales del Instituto de la Patagonia, Serie Ciencias Sociales, 18:79-94.

EMPERAIRE, J. y A. LAMING 1961. Les Gisements des iles Englefield et Viviam dans la mer d'Otway (Patagonia Australe). Journal de la Societe des Americanistes, 50:7-77. Traducción: L. Orquera.

ENDLICHER, W. y A. SANTANA 1988. El clima del sur de la Patagonia y sus aspectos ecológicos. Un siglo de mediciones climatológicas en Punta Arenas. Anales del Instituto de la Patagonia. Serie Cs.Naturales, 18:57-86.

FRANGI, J., M. D. BARRERA, J. PUIGDEFÁBREGAS, P. YAPURA, A. ARAMBARRI y L. RICHTER 2005. Ecología de los bosques de Tierra del Fuego. En: Ecología y manejo de los bosques de Argentina. Editorial de la Universidad Nacional de La Plata (EDULP), La Plata.

GIBBONS, J, F GAZITÚA \& C VENEGAS. 2000. Cetáceos en el estrecho de Magallanes y Senos Otway, Skyring y Almirantazgo. Anales del Instituto de la Patagonia, Serie Ciencias Naturales 28: 107-118.

KELLY, R. 1995. The Foraging Spectrum. Diversity in HunterGatherers Lifeways. Smithsonian Institution, Washington.

LAMING-EMPERAIRE, A. 1972. Pêcheurs des archipels et chasseurs des pampas. Objets et Mondes, 12(2):167-184. 1976. Le plus ancien peuplement de 1'Amerique. Bulletin de la Société Préhistorique Française, C.R.S.M. 13 (9):280-287.

LEGOUPIL, D. 1988. Ultimas consideraciones sobre las dataciones del sitio de Isla Englefield (seno Otway). Anales del Instituto de la Patagonia, Serie Ciencias Sociales, 18: 95-98. 2000. El sistema socioeconómico de los nómades del mar de Skyring (Archipiélago de Patagonia). Anales del Instituto de la Patagonia, Serie Ciencias Humanas, 28:81-119.

2003. Cazadores-recolectores de Ponsonby (Patagonia austral) y su paleoambiente desde VI al III milenio AC. Magallania, 31, tirada especial. 
LEGOUPIL, D. y M. FONTUGNE 1997. El poblamiento marítimo en los archipiélagos de la Patagonia: núcleos antiguos y dispersión reciente. Anales del Instituto de la Patagonia, 25:75-87.

LUEBERT, F. y P. PLISCOFF 2009. Sinopsis bioclimática y vegetacional de Chile. Disponible en Internet: http:// territorial.sinia.cl.

MAGAZZÙ, G.; S. PANELLA y F. DECEMBRINI 1996. Seasonal variability of fractionated phytoplankton, biomass and primary production in the Straits of Magellan. Journal of Marine Systems, 9: 249-267.

MANZI, L. 2004. La obsidiana verde como indicador de formas de uso del espacio en Fuego Patagonia. En: Contra viento y marea. Arqueología de Patagonia. V Jornadas de Arqueología de la Patagonia. Civalero, T., Fernández, P. y G. Guraiéb (eds.), INAPL, pp: 117-134, Buenos Aires.

MARTINIC, M. 1989. Los canoeros de la Patagonia meridional. Poblacion historica y distribucion geografica (siglos XIX y XX). El fin de una etnia. Journal de la Société des Américanistes, XXV: 35-61.

MASSONE, M. 2004. Los cazadores después del hielo. Ediciones de la Dirección de la Biblioteca de Archivos y Museo, Santiago de Chile.

MASSONE, M. y A. PRIETO 2004. Evaluación de la modalidad cultural Fell 1 en Magallanes. Chungara Volumen especial, pp. 303-315.

MERCER, J. 1970. Variations of some Patagonian glaciers since the lateglacial: II. American Journal of Science, 269:1-25

McCULLOCH, R., CH. CLAPPERTON, J. RABASSA y A. CURRANT 1997. The natural Setting. The glacial and Post-Glacial environmental history of Fuego-Patagonia. En: Patagonia, editado por C. Mc Ewan, L. Borrero y A. Prieto, 12-31. British Museum Press, Londres.

McCULLOCH, R.D. y S.J. DAVIES 2001. Late-glacial and Holocene palaeoenvironmental change in the central Strait of Magellan, southern Patagonia. Palaeogeography, Palaeoclimatology, Palaeoecology, 173:143-173.

McCULLOCH, R., C. FOGWILL, D. SUGDEN, M.BENTLEY y P. KUBIK 2005. Chronology of the Last Glaciation in Central Strait of Magullan and Bahía Inútil, Southernmost South America. Geografiska Annaler, 87(A):289-312.

McCULLOCH, R. y F. MORELLO 2009. Fijando la escena: evidencia glacial y paleoecológica de los ambientes tardiglaciales y del Holoceno temprano en Fuego-Patagonia. En: Arqueología de Patagonia: Una mirada desde el último confín, editado por M. Salemme, F. Santiago, M. Álvarez, E. Piana, M. Vázquez y M. Mansur, 119-136. Editorial Utopías, Ushuaia.
MORELLO, F., L. CONTRERAS y M. SAN ROMÁN 1999. La localidad de Marazzi y el sitio arqueológico Marizzi-1, una re-evaluación. Anales del Instituto de la Patagonia, 27:183-197.

MORELLO, F., M. SAN ROMÁN y A. PRIETO 2004. Obsidiana verde en Fuego-Patagonia: distribución y estrategias tecnológicas. En: Contra viento y marea. Arqueología de Patagonia. M. T. Civalero, P. M. Fernández y A. G. Guraieb (eds.). Instituto Nacional de Antropología y Pensamiento Latinoamericano y Sociedad Argentina de Antropología, 149-166, Buenos Aires.

MORELLO, F., M. SAN ROMÁN, A. PRIETO y CH. STERN 2001. Nuevos avances para una discusión arqueológica en torno a la obsidiana verde en Patagonia Meridional. Anales del Instituto de la Patagonia, 29:129-148.

OCAMPO, C. y P. RIVAS 2000. Nuevos fechados ${ }^{14} \mathrm{C}$ de la costa norte de la isla Navarino, costa sur del canal Beagle, provincia Antártica Chilena. Región de Magallanes. Anales del Instituto de la Patagonia, 28:197-214.

OLAVE-SOLAR, C., A. SANTANA, N. BUTOROVIC y P. ACUÑA 2008. Variabilidad térmica en la región nororiental de la península de Brunswick, Magallanes, Chile, empleando datos Landsat. Anales del Instituto de la Patagonia, 36(2):5-12.

ORTIZ TRONCOSO, O. 1975 Los yacimientos de Punta Santa Ana y Bahía Buena (Patagonia Austral). Excavaciones y fechados radiocarbónicos. Anales del Instituto de la Patagonia, 6 (1-2):93-122.

1979 Punta Santa Ana et Bahía Buena: Deux gisements sur une ancienne ligne de rivage dans le détroit de Magellan. Journal de la Société des Américanistes, 66:133-204.

1989 Ancestros de los pescadores australes $(8.000$ a.C. a ca. 1.500 d.C.)". En: Desde sus orígenes hasta los albores de la conquista. Jorge Hidalgo, Virgilio Schiappacasse, Hans Niemeyer, Carlos Aldunate e Iván Solimano (Eds.), Editorial Andrés Bello, pp. 367-379. Santiago de Chile.

PALMA, S. 2006. Distribución y abundancia de zooplancton en canales y fiordos australes. En: Avances en el conocimiento oceanográfico de las aguas interiores chilenas, puerto Montt a cabo de Hornos. N. Silva y S. Palma (eds.). Comité Oceanográfico Nacional-Pontificia Universidad Católica de Valparaíso, pp. 107-113, Valparaíso.

PANELLA, S., A. MICHELATO, R. PERDICARO, G. MAGAZA, I. DECEMBRINI y P. SCARAZZATO 1991. A preliminary contribution to understanding the hydrological characteristics of the Strait of Magelllan: austral spring 1989. Memoria Biology Marine Oceanography, 19:65-75. 
PISANO, E. 1977. Fitogeografía de Fuego-Patagonia Chilena. I. Comunidades vegetales entre las latitudes $52^{\circ}$ y $57^{\circ}$ S. Anales del Instituto de la Patagonia, 8:121-250.

PIZARRO-SOLARI C. A. 2004. Áreas marinas protegidas y su utilidad en la conservación de las aves marinas en Chile. Tesis para Titulo de Biólogo. Universidad de Chile, p: 114. Disponible En: h ttp://www.cybertesis. cl/tesis/uchile.

PRIETO, A., CHEVALLAY, D. y O. OVANDO 2000. Los pasos de indios en Patagonia Austral. En Desde el país de los Gigantes. Perspectivas arqueológicas en Patagonia. Tomo 1:87-94. UNPA, Río Gallegos.

PRIETO, J. y M. WINSLOW 1992. El cuaternario del Estrecho de Magallanes I: sector Punta Arenas Primera Angostura. Anales del Instituto de la Patagonia, 21:85-95.

RABASSA, J., A. CORONATO, S. GORDILLO, M. S. CANDEL y M. A. MARTÍNEZ 2008. El inicio de la trasgresión marina holocena en el canal Beagle, Parque Nacional Tierra del Fuego. $12^{\circ}$ Congreso Geológico Argentino, Actas: 889-890, San Salvador de Jujuy.

SAG. 2003 El pastizal de Tierra del Fuego. Guía de Uso, Condición Actual y Propuesta de Seguimiento para Determinación de Tendencia. Ed. por Servicio Agrícola y Ganadero, Depto. de Protección de los Recursos Naturales Renovables, Santiago de Chile.

2004. El pastizal de Magallanes. Guía de Uso, Condición Actual y Propuesta de Seguimiento para Determinación de Tendencia. Ed. por Servicio Agrícola y Ganadero, Depto. de Protección de los Recursos Naturales Renovables, Santiago de Chile.

SALINAS, S., M. CONTRERAS y J. FIERRO 2004. Propagación de la onda de marea en el estrecho de Magallanes. Ciencia y Tecnología del Mar, 27(2):5-20.

SAN ROMÁN, M. 2005. Nuevos hallazgos de sitios de cazadores recolectores marítimos tempranos en isla Englefield, mar de Otway. Magallania, 33(2):173-176.

2010. La explotación de recursos faunísticos en el sitio Punta Santa Ana 1: estrategias de subsistencia de grupos de cazadores marinos tempranos de Patagonia Meridional. Magallania, 38 (1):183-198

2011. Sitios arqueológicos de isla Englefield, mar de Otway: Nuevas evidencias de discontinuidad cultural en el proceso de poblamiento marítimo de Patagonia meridional. Poster presentado en las VIII Jornadas de Arqueología de la Patagonia, Malargüe, 3 al 7 de octubre.

SAN ROMÁN, M., F. MORELLO y A. PRIETO 2002. Nuevos antecedentes sobre la explotación de recursos faunísticos en el mar de Otway y canales adyacentes. Anales del
Instituto de la Patagonia, Serie Ciencias Humanas, 30:147-154.

SAN ROMÁN, M, K. SALAS y M. FONTUGNE 2009. Primeros avances en la reconstrucción de secuencias de ocupación de cazadores recolectores marinos en el estrecho de Magallanes, Patagonia meridional. En: Arqueología de Patagonia: una mirada desde el último confín. (eds.). Salemme F. S. M., M. Alvarez, E. Piana, M. Vázquez y E. Mansur, Editorial Utopías, pp. 35-45. Ushuaia.

SANTANA, A., C. OLAVE y N. BUTOROVIC 2010. Estudio climatológico con registros de alta resolución temporal en Campamento Posesión (ENAP): Magallanes, Chile. Anales del Instituto de la Patagonia (Chile) [online] vol.38, n.1 [citado 2011-09-25], pp. 5-34. Disponible en: www.scielo.cl/scielo.

SASSI, M. y E. D. PALMA 2006. Modelo hidrodinámico del estrecho de Magallanes. Congreso. ENIEF 2006. Asociación Argentina de Mecánica Computacional, Santa Fe.

SHOA 2009. Boletín de noticias a los navegantes $n^{\circ}$ 6. Publicación Servicio Hidrográfico y Oceanográfico de la Armada de Chile 3500.

2010. Boletín de noticias a los navegantes $n^{\circ}$ 4. Publicación Servicio Hidrográfico y Oceanográfico de la Armada de Chile 3500.

SIELFELD W, C. VENEGAS y A ATALAH 1979. Consideraciones acerca del estado de los mamíferos marinos en Chile. Anales del Instituto de la Patagonia, 8: 297-318.

SOLARI, M. E. 2007. Historia Ambiental Holocénica de la Región sur-austral de Chile (X -XII región). Revista Austral de Ciencias Sociales. Disponible en Internet: http://redalyc.uaemex.mx/redalyc/src/inicio/ArtPdfRed. jsp?iCve=45901306. ISSN 0717-3202

STERN, CH. y A. PRIETO 1991. Obsidiana verde de los sitios arqueológicos en los alrededores del mar de Otway, Magallanes, Chile. Anales del Instituto de la Patagonia, 20:139-144.

STINE, S. 1994 Extreme and persistent drought in California and Patagonia during medieval time. Nature, 369:546-549.

STUART, D. E. 1983. Subsistencia yahgan y patrones de movilidad en canoas. Arqueología Contemporánea, 1(1): 20-27.

URIBE, P.C. y E.M. ZAMORA 1981. Origen y morfología de la Punta Dungeness, Patagonia. Anales del Instituto de la Patagonia, 12:143-158.

VALDENEGRO, A. y N. SILVA 2003. Caracterización oceanográfica física y química de la zona de canales y fiordos australes de Chile entre el estrecho de Magallanes y Cabo de Hornos (CIMAR 3 FIORDOS). Ciencia y Tecnología del Mar, 26 (2):19-60. 
VENEGAS, C. 2001. Cuantificación poblacional de lobos marinos en la XII región. Informe Final Proyecto FIP no 2000 - 22. Universidad de Magallanes, Instituto de la Patagonia, Punta Arenas. MS.

VENEGAS, C. y W. SIELFELD 1979. Antecedentes para la determinación de un nuevo distrito zoogeográfico en el litoral exterior de Magallanes. Anales del Instituto de la Patagonia, 10: 201-208.
VETH, P.M. 1993. Islands in the Interior. The Dynamics of Prehistoric Adaptations within the Arid Zone of Australia. Ann Arbor (ed.), International Monographs in Prehistory, Archaeological Series 3.

WHALLON, R. 2006. Social networks and information: Non"utilitarian" mobility among hunter-gatherers. Journal of Anthropological Archaeology, 25: 259-270. 